\title{
Ethical Perspectives on Stem Cell-based Cellular Therapies for Neurodegenerative Diseases
}

\section{Mette Ebbesen ${ }^{1 *}$, Finn Skou Pedersen ${ }^{2,3}$, Svend Andersen ${ }^{4}$ and Thomas G. Jensen ${ }^{5}$}

${ }^{1}$ Centre for Bioethics and Nanoethics, Faculty of Arts, Aarhus University, DK-8000 Aarhus C, Denmark

${ }^{2}$ Interdisciplinary Nanoscience Center (iNANO), Aarhus University, DK-8000 Aarhus C, Denmark

${ }^{3}$ Department of Molecular Biology and Genetics, Aarhus University, DK-8000 Aarhus C, Denmark

${ }^{4}$ Faculty of Arts, Aarhus University, DK-8000 Aarhus C, Denmark

${ }^{5}$ Department of Biomedicine, Aarhus University DK-8000 Aarhus C, Denmark

\begin{abstract}
The effect of stem cell-based therapies for neurodegenerative diseases such as Alzheimer disease, Huntington disease, and Parkinson disease are currently being investigated. Here we specify possible therapeutic effects and possible side effects for patients and conclude that cellular therapies may have benefits for patients. The side effect described most commonly in the literature is the risk of tumor formation by stem cells not fully differentiated into neurons when transplanted or following viral transduction and subsequent differentiation to create induced pluripotent stem cells. This risk may be avoided by differentiating stem cells in culture before transplantation.

Here we argue that the following ethical considerations are important for clinical trials: Informed consent of research subjects or patients, specification of possible therapeutic effects, risk analysis of possible side effects, equitable access of patients to clinical trials, and adequate compensation should be paid to research subjects or patients. We clarify that the related ethical principles are respect for autonomy, beneficence, nonmaleficence, and justice and that the ethical theory of the American ethicists Tom L. Beauchamp and James F. Childress is based on these principles. We show that this theory is useful for analyzing complex ethical cases of biomedicine by using cellular therapy for neurodegenerative diseases as a model system. We go through the three steps in
\end{abstract} an ethical case analysis using Beauchamp and Childress' principles.

We explain that the ethical issues of using stem cells for therapies for neurodegenerative diseases often referred to in the literature are related to the moral status of the blastocyst and the developing embryo. We believe that these are to be seen as potential human life with increasing moral status during development. We propose that they should be treated with increasing respect and only used for research where no other cells as source for transplantation are available.

\section{Introduction}

Neurodegenerative diseases are characterized by loss of neurons in the brain or the spinal cord. They include diseases such as Alzheimer disease, Huntington disease, and Parkinson disease, for which no effective treatments have been found. These severe diseases lead to loss of life quality for affected individuals and large health care costs for society. Recently, neurons have been generated from various types of stem cells and transplanted into the brain of animal models and research subjects showing promise as potential future therapies for neurodegenerative diseases. Thus both animal studies and clinical trials have shown positive results through the use of stem cells for cellular replacement as well as for providing environmental enrichment to diminish the degeneration of neurons [1-4]. However, cellular therapies are complicated, and many issues need to be addressed for each neurodegenerative disease before studies and trials can be started. According to Lunn et al. [1] and Kim and de Vellis [2], these issues include what kind of stem cells would be the best source for a given disease, what are the mechanisms that lead to recovery, what are the potential side effects of that specific cell-based therapy, what results do we expect, and what are the inclusion/exclusion criteria of research subjects for the clinical trials? These topics have ethical components, including the ethical concepts of respect for autonomy, beneficence, nonmaleficence, and justice. Later in this article we will illustrate how these ethical concepts are entangled in the scientific issues which Lunn et al. [1] and Kim and de Vellis [2] propose that we need to address before studies and clinical trials can be started. For instance, 'potential side effects' have to do with nonmaleficence, 'results of clinical trials' have to do with the ethical concepts of informed consent (respect for autonomy) of the research subject and beneficial/maleficent output of testing new treatments, and 'inclusion/exclusion criteria' have to do with just selection of research subjects.
The American ethicists Beauchamp and Childress [5] have developed an ethical theory of principles, which specifically includes the mentioned ethical concepts of respect for autonomy, beneficence, nonmaleficence, and justice. Beauchamp and Childress believe that morally serious persons all know such rules as that of telling the truth, nurturing the young and dependent, not to kill, not to steal etc. According to Beauchamp and Childress, we all know these rules since they are part of a universal common morality, and each specific rule corresponds to one or more of the abstract principles of respect for autonomy, beneficence, nonmaleficence, and justice. These principles form the foundation of the common morality and specifically, they are useful to analyze ethically complex cases of biomedicine such as cellular therapies.

In this article we focus on examining ethical perspectives of cellular therapies for neurodegenerative diseases. First, we outline cellular therapy classifications and consider how these may be applied to neurodegenerative diseases in the future. Next, we study ethical issues of clinical trials regarding cellular therapy for neurodegenerative diseases. This study includes a presentation of the ethical theory of

*Corresponding author: Mette Ebbesen, Centre for Bioethics and Nanoethics, Faculty of Arts, Aarhus University, Taasingegade 3, Bldg. 1443, DK-8000 Aarhus C, Denmark, Tel: +45 8942 2312; E-mail: meb@teo.au.dk

Received December 16, 2011; Accepted April 13, 2012; Published April 16, 2012

Citation: Ebbesen M, Pedersen FS, Andersen S, Jensen TG (2012) Ethica Perspectives on Stem Cell-based Cellular Therapies for Neurodegenerative Diseases. J Cell Sci Ther S3:003. doi:10.4172/2157-7013.S3-003

Copyright: (C) 2012 Ebbesen M, et al. This is an open-access article distributed under the terms of the Creative Commons Attribution License, which permits unrestricted use, distribution, and reproduction in any medium, provided the original author and source are credited. 
Beauchamp and Childress and an examination of the three steps in an ethical analysis.

\section{Cellular Therapies for Neurodegenerative Diseases}

Chronic neurodegenerative diseases may result in the loss of neurons in the brain over a long time range or the loss of a specific neuronal subtype in a localized area in the brain. Here, we focus on the neurodegenerative diseases of Parkinson Disease (PD), Alzheimer Disease (AD), and Huntington Disease (HD). PD involves specific death of dopamine-generating neurons (DA neurons) in a localized region in the midbrain (the substantia nigra pars compacta), whereas $\mathrm{AD}$ and HD cause a general loss of neurons in the brain. No efficient and causative treatments exist for these diseases, however, cell-based therapies are promising candidates for future therapies and this field is rapidly advancing [1-4]. In the current section, we describe stem cell sources for transplantation.

\section{Stem cell sources for transplantation}

Various stem cells are being tested for therapies for neurodegenerative diseases due to their capacity to differentiate into specific cell types such as neurons. In general, stem cells can divide and differentiate into various cell types, and they can furthermore renew themselves producing more stem cells. The human body produces different kinds of stem cells mirroring the types of cells they can differentiate into and their source of origin. Stem cells include Embryonic Stem cells (ES cells), progenitor cells such as Neural Progenitor Cells (NPCs), Mesenchymal Stem Cells (MSCs), and induced Pluripotent Stem cells (iPS cells). ES cells can be isolated from the inner cell mass of the blastocyst and can differentiate into all specialized cells in the body (they are pluripotent). The isolation of ES cells from the inner cell mass of the blastocyst involves the use of an embryo which causes specific ethical and religious issues. Progenitor cells can be isolated from more differentiated tissues and give rise to fewer cell types than ES cells (they are categorised as multipotent cells). Their capacity is often determined by the kind of germ layer from where the progenitor cells originate. For instance, NPCs are isolated from neural tissue and they are able to differentiate into neurons. MSCs are adult stem cells found in the bone marrow (these cells are also categorised as multipotent cells). MSCs are able to differentiate into restricted cell types including cells in the neural lineage. Since MSCs can be derived from an autologous source (from one part of the body to another in the same individual) they may avoid or reduce immunological rejection and thereby the need for immunosuppression. In the case of a genetic disease such as $\mathrm{HD}$ it is not preferable to use cells from an autologous source since these cells will also contain the disease-causing mutation. Umbilical cord blood (CB) can be isolated from newborns right after delivery. $\mathrm{CB}$ contains different types of stem cells including immature stem cells, hematopoietic stem cells, endothelial stem cells, epithelial stem cells, mesenchymal stem cells, and unrestricted somatic stem cells [6]. In several studies on cellular therapies for neurodegenerative diseases using CB stem cells, mesenchymal stem cells have been the preferred cell type [7-9]. Some of the stem cells from CB have the ability to undergo pluripotential differentiation and they occupy an intermediate age stage between ES cells and adult stem cells meaning that they have a higher proliferating potential and longer telomeres than other types of somatic stem cells $[6,10]$. Since cells isolated from CB have the advantage of being immunologically immature, immunosuppressive therapy may not be necessary upon transplantation [11]. Numerous public and private agencies offer storage of CB for later uses $[6,10]$. Lastly, iPS cells are pluripotent cells derived by reprogramming of adult somatic cells such as fibroblasts. They can be generated using expression of a specific combination of transcription factors through viral transduction. Hence, in terms of their potential to give rise to cells of various lineages iPS cells are related to ES cells [1-4].

\section{Cellular therapy for Parkinson disease, Alzheimer disease, and Huntington disease}

Cell-based therapies often include either cellular replacement or environmental enrichment. Concerning cellular replacement, transplanted cells may re-establish, improve, or stabilize neural networks. Regarding environmental enrichment, stem cells can be used to synthetize neuroprotective growth factors, provide support for cells still remaining, or hinder that toxic factors damage neurons at the affected site [1].

Cellular therapy for Parkinson disease (PD): PD is characterized by the progressive loss of muscle control resulting in shaking, rigidity, and slowness of movement. These symptoms result from the death of DA neurons in the substantia nigra. As the disease progresses symptoms also include cognitive and behavioral difficulties. PD is most prevalent among elderly persons. Current treatments include dopamine agonists, however, as the disease evolves and dopamine generating cells are lost, this treatment may be unsuccessful and some patients are also treated with surgery or deep brain stimulation to reduce motor deficits $[1,2]$.

Cellular therapies aim at replacing lost DA neurons (cellular replacement). DA neurons have been harvested from fetal tissue and transplanted into patients. These trials disclosed variable and mostly negative results and they demonstrated that some research subjects developed side-effects such as involuntary movements, so-called graft-induced dyskinesias [12]. However, other clinical trials have shown that patients have exhibited marked symptomatic relief after transplantation of DA neurons from fetal tissue, however, to improve the clinical outcome the survival of the cells from transplanted fetal tissue has to be increased [13].

ES cells can be differentiated into DA neurons by adding factors normally involved in DA development [4]. These DA neurons have been transplanted into rat models, which led to functional recovery $[1,2,4]$. However, if not all ES cells transplanted are fully differentiated into DA neurons upon transplantation there is a certain risk of tumorigenicity. In rat models tumor formation from such cells has been reported $[3,4]$. Similar to the use of transplanted fetal tissue, DA neurons derived from ES cells have the disadvantage that they origin from a non-autologous source and therefore, there is a risk of immune rejection [4]. Therefore, the use of iPS cells to produce patient-specific DA neurons is investigated. In several experiments fibroblasts from patients were reprogrammed by viral transduction and subsequently differentiated in culture into DA neurons (iPS cells). These iPS cells were then transplanted into a PD rodent model leading to improved functional deficits and causing cells to integrate into the tissue of the animal $[1,14]$. A major concern with some of the methods used for generating iPS cells is the risk of using viral vectors for transduction and the subsequent risk of tumor formation [3].

Environmental enrichment has also been investigated as a means to maintain remaining DA neurons and stop further degeneration. MSCs and NPCs were designed to produce growth factors such as GlialDerived Neurotrophic Factor (GDNF), Brain-Derived Neurotrophic Factor (BDNF), Insulin-like Growth Factor-I (IGF-I), and Vascular Endothelial Growth Factor (VEGF). Transplantation of these engineered cells in a PD rodent model led to DA neuronal protection 
and the promotion of functional recovery $[1,7,15]$. Mesenchymal stem cells from CB (Human Umbilical cord Mesenchymal Stem Cells (HUMSCs)) have been modified by VEGF gene transfer and transplanted into parkinsonian rats. The VEGF expression enhanced HUMSC-differentiation into dopaminergic neuron-like cells. Parkinsonian rats receiving modified HUMSC showed a significant normalization of the phenotype and reduced loss of dopaminergic neurons in the lesioned substantia nigra [7]. Similar results to those found by Xiong et al. [7] were obtained by Li et al. [8].

Hence, both cellular replacement and environmental enrichment have shown progress as potential candidates for future treatment of PD.

Cellular therapy for Alzheimer disease (AD): AD is a progressive disease, in which memory and cognitive skills are slowly declining. $\mathrm{AD}$ is the most common form of dementia. This disease may develop undiagnosed for several years and the first symptoms can mistakenly be interpreted as age-related concerns such as memory loss and confusion. Often persons diagnosed with $\mathrm{AD}$ are over 65 years of age. When $\mathrm{AD}$ progresses later symptoms also count irritability and aggression. These symptoms are due to a widespread loss of neurons and synaptic contacts throughout the brain. Contemporary treatments of $\mathrm{AD}$ do not stop the disease from progressing; however, they affect symptoms such as behavioral and cognitive defects by enhancing cholinergic function $[1,2]$.

Since stem cells can migrate when transplanted into the brain and they can be genetically modified to express new genes, they are good candidates for treating AD. Expression of growth factors may provide environmental enrichment to protect and enrich surviving neurons. For instance, stem cells can be modified to express nerve growth factor (NGF), which hinders neuronal death and improves memory in animal models of aging [2]. Also, fibroblasts expressing NGF from patients have been tested in a phase I clinical trial, in which these fibroblasts were transplanted into a cholinergic center in the brain and caused some benefits to patients [1]. A Danish biopharmaceutical company NsGene is currently developing a therapy for AD based on encapsulated human epithelial cells genetically modified to secrete NGF $[16,17]$. In preclinical studies NGF secreting cells were implanted into the basal forebrain of Göttingen minipigs. It was found that the implants were well tolerated by the pigs and functionally active upon explantation [16]. A clinical phase 1b trial was initiated in 2008 with 6 enrolled patients who underwent 12 months of therapy. The final outcomes of this study have not yet been published, but according to Fjord-Larsen et al. [17] the results are promising. In order to be able to increase the dose of NGF, a system was designed based on transposonmediated transfer of the transgenes. In this way multiple copies of the transgenes were inserted between two transposon terminal inverted repeats resulting in a 10-fold higher NGF expression compared to the initial construct mentioned above generated by using standard transfection techniques [17].

The level of BDNF is lowered in $\mathrm{AD}$ patients and increasing BDNF causes environmental enrichment by supporting host neurons resulting in neurogenesis and protection of neuronal function. For instance, NPC grafts were transplanted into rodent AD models along with BDNF enhancement, which resulted in increased synaptic density and cognitive function [1].

Not only the death of neurons and the reduced synthesis of the neurotransmitter acetylcholine are the main reasons to cause $\mathrm{AD}$. Thus several studies have shown that misfolding and aggregation of proteins such as extracellular $\beta$-amyloid (A $\beta$ ) deposits and intracellular hyperphosphorylated tau ( $\mathrm{p}$-tau) may play an important role during $\mathrm{AD}$ formation. Aggregation of $\mathrm{A} \beta$ causes downstream loss of dendrites and synapses and disruption of neuronal networks. Increasing levels of $A \beta$ is an early cause in the chain of events that leads to aggregation of tau protein, neuronal dysfunction, and dementia. By progressing age, the level of $A \beta$ increases in the brain and this is highly probably due to the impaired protein quality control processes. Studies indicate that the increased level of $\mathrm{A} \beta$ initiates a decade before the onset of AD. Thus, it would be necessary to impede the seeding cascade of $A \beta$ for cellular therapies to be effective against $\mathrm{AD}[18,19]$. The possible impact of in vitro co-cultivation of HUMSCs with hippocampal neurons treated with $A \beta$ was studied by Lee et al. [9]. In this study $A \beta$ lead to reduced hippocampal apoptosis. Furthermore, HUMSCs transplanted into an $\mathrm{AD}$ mouse model led to glial activation and reduction in oxidative stress and apoptosis in the brains of the mice. Furthermore, AD mice transplanted with HUMSCs showed a restoring of memory and learning functions [9].

Cellular therapy for Huntington disease (HD): $\mathrm{HD}$ is a neurodegenerative genetic disease caused by an autosomal dominant mutation in the huntingtin gene. The mutated form of the protein coded by this gene causes gradual damage in specific areas of the brain affecting muscle coordination and leading to cognitive decline, dementia, and personality changes resulting from the progressive loss of medium spiny neurons (MSNs) in the brain. Symptoms often begin when affected persons are middle-aged. Despite identification of the genetic basis of the HD, the mechanisms involved in the pathology of this disease are not completely understood which makes it difficult do design effective therapies [1,2]. Both cellular replacement and environmental enrichment for HD have been studied. MSNs were harvested from fetal tissue and transplanted into HD rodent models and HD patients. In rodents, MSNs integrated and formed circuitry in the animal [20]. The treated HD patients showed minor temporary progress before inherent degeneration of neurons in a pattern similar to that observed in HD itself $[21,22]$. Also, primed NPCs have been transplanted into a HD rat model and showed to accelerate sensorimotor function outcome [23]. For environmental enrichment NPCs were modified to overexpress the growth factor GDNF (which promotes the survival of many types of neurons) and transplanted into HD rodent models. This study demonstrated neuronal protection and functional recovery [1]. In HD, cellular therapy has shown most promising results in animal models. In patients, transplanted cells show a disease pattern similar to that of the disease itself 10 years after transplantation (even though transplanted cells do not contain the mutation of HD). This is to be seen in contrast to the grafted cells in Parkinson disease, in which the transplanted DA neurons remain viable, however, down-regulated [22].

Lunn et al. [1] conclude that stem cells for both cellular replacement and environmental enrichment show great promise for future treatment of neurodegenerative diseases, in general. However, since the pathophysiology of each neurodegenerative disease is distinctive careful attention to each component of a clinical trial is required. We will look into these components of clinical trials in the next section.

\section{Ethical Issues of Clinical Trials Regarding Cellular Therapy for Neurodegenerative Diseases}

Lunn et al. [1] made some common considerations regarding each component of clinical trials for cellular therapies for neurodegenerative diseases. Some of these considerations are presented in Table 1. 


\begin{tabular}{|c|c|c|c|}
\hline $\begin{array}{c}\text { General considerations } \\
\text { regarding clinical trials Lunn et } \\
\text { al. [1] }\end{array}$ & $\begin{array}{l}\text { Detailed description of the general considerations } \\
\text { Lunn et al. [1] }\end{array}$ & Ethical considerations & Related basic ethical principles \\
\hline $\begin{array}{l}\text { Inclusion/exclusion criteria for } \\
\text { patients }\end{array}$ & Early stage or late stage patients? & $\begin{array}{l}\text { Provide equitable access of research } \\
\text { subjects or patients (fairness) }\end{array}$ & Justice \\
\hline \multirow{3}{*}{ Realistic expectations } & $\begin{array}{l}\text { Informed consent forms must tell the patient about } \\
\text { the trial }\end{array}$ & Informed consent & Respect for autonomy \\
\hline & Safety trials versus efficacy trials & $\begin{array}{l}\text { Health impact } \\
\text { Risk-benefit analysis }\end{array}$ & Beneficence and nonmaleficence \\
\hline & Expectations of therapeutic effect & $\begin{array}{l}\text { Health impact } \\
\text { Risk-benefit analysis }\end{array}$ & Beneficence \\
\hline Immunosuppression & $\begin{array}{l}\text { Immunosuppression may increase the survival of } \\
\text { graft tissue }\end{array}$ & $\begin{array}{l}\text { Health impact } \\
\text { Risk-benefit analysis }\end{array}$ & Beneficence and nonmaleficence \\
\hline \multirow{2}{*}{ Potential side effects } & $\begin{array}{l}\text { Prevent or minimize potential side effects (for } \\
\text { instance tumor formation) }\end{array}$ & $\begin{array}{l}\text { Health impact } \\
\text { Risk-benefit analysis }\end{array}$ & Beneficence and nonmaleficence \\
\hline & Risk versus quality of life & $\begin{array}{l}\text { Health impact } \\
\text { Risk-benefit analysis }\end{array}$ & Beneficence and nonmaleficence \\
\hline $\begin{array}{l}\text { Safety of cellular therapy } \\
\text { administration }\end{array}$ & $\begin{array}{l}\text { Pros and cons of systemic delivery, lumbar puncture, } \\
\text { or stereotactic injection }\end{array}$ & $\begin{array}{l}\text { Health impact } \\
\text { Risk-benefit analysis }\end{array}$ & Beneficence and nonmaleficence \\
\hline
\end{tabular}

Table 1: Common considerations regarding each component of clinical trials for cellular therapies for neurodegenerative diseases by Lunn et al. [1].

The first two columns of Table 1 present the views of Lunn et al. [1] regarding each component of clinical trials for cellular therapies for neurodegenerative diseases. In the third and fourth columns we have specified which ethical considerations and basic ethical principles are related to each component. For instance, the component inclusion/ exclusion criteria for patients or research subjects' is related to the ethical consideration of providing just access to clinical trials (fairness). Another example is the component 'realistic expectations of clinical trials'. Informed consent forms must tell the patient about the trial, its expectations, possible side effects etc. This component is related to the ethical consideration of informed consent. 'Realistic expectations' also have to do with the expectations of therapeutic effects, which are related to the ethical considerations of health impacts.

From Table 1, we can see that the ethical considerations of clinical trials for cellular therapies for neurodegenerative diseases fall into three classifications: 1) Fairness, 2) Informed consent, and 3) Risk-benefit analysis. Here, we will show which basic ethical principles are related to these classifications of ethical considerations.

\section{Fairness}

Often the concept of fairness is associated with the distribution of goods and burdens. If goods are in short supply in society it is important to have valid principles of justice to determine how these goods can be allocated fairly. Hence, the term fairness is associated with ethical principles of justice [5].

\section{Informed consent}

The term informed consent is closely related to the ethical principle of respecting the autonomy of the patient or the research subject, since informed consent is based upon the notion that the patient giving consent is able to act autonomously which is to act intentionally, with understanding, and without controlling influences that determine her or his action [5]. Hence, the justification of informed consent is to protect the autonomous choice of the patient or the research subject.

\section{Risk-benefit analysis}

A risk-benefit analysis is an assessment of probable risks in relation to probable benefits, which is a ratio between "the probability and magnitude of an anticipated benefit and the probability and magnitude of an anticipated harm" [5]. A risk-benefit analysis is often followed by risk management which is to judge how much risk is acceptable.
Basically, a risk-benefit analysis is a balancing of the principles of nonmaleficence and beneficence.

Above, we have argued that the four basic ethical principles at stake in clinical trials for cellular therapies for neurodegenerative diseases are the principles of justice, respect for autonomy, beneficence, and nonmaleficence. Beauchamp and Childress base their bioethical theory on these principles and we believe that this theory is a well-argued approach to analyze the ethical issues of clinical trials for cellular therapy for neurodegenerative diseases. In the next section we will present the ethical theory of Beauchamp and Childress.

\section{Method for Case Analysis in Biomedical Ethics}

Many approaches can be chosen for analyzing problems in biomedical ethics such as the ones discussed in this article. In our view, Beauchamp and Childress' cross cultural ethical theory based on principles is the most fruitful starting point. The principles they promote are well-known: Respect for autonomy, beneficence, nonmaleficence, and justice. The principles justify or correspond to some moral rules: For instance, the rule 'Do not kill' is justified by the principle of nonmaleficence, the rule 'Tell the truth' is justified by the principle of respect for autonomy, the rule 'Prevent evil or harm from occurring' is justified by the principle of beneficence, the rule 'Obey the law' is justified by the principle of justice. In Figure 1 [24], a short formulation of the four principles is presented.

Beauchamp and Childress believe that morally serious persons share these moral rules in common and that the rules are cross cultural; hence American, Japanese, and Italian people know them. Since, the rules are cross cultural, they have normative force in spite of cultural differences and we can judge cultures by use of or according to these rules. If persons do not live up to these rules they are immoral. The principles and the rules constitute the foundation of the universal common morality and Beauchamp calls this 'morality in the narrow sense'. From this point of view there is no difference between American, Japanese, and Italian morality. However, different moralities do exist [25] the common rules and principles are specified differently in different cultures because of "different philosophical, religious, or cultural commitments" [25] And this is what Beauchamp calls morality 'in the broad sense'. Beauchamp puts it: "In all cultures the interpretation and specification of norms, the reconstruction of traditional beliefs, the balancing of different values, and negotiation are essential on an ongoing basis" [25] So, whereas morality in the narrow 


\section{The principle of respect for autonomy}

- "As a negative obligation: Autonomous actions should not be subjected to controlling constraints by others" ([5] p. 104).

- "As a positive obligation, this principle requires both respectful treatment in disclosing information and actions that foster autonomous decision making" ([5] p. 104). Furthermore, this principle obligates to "disclose information, to probe for and ensure understanding and voluntariness, and to foster adequate decision making" ([5] p. 104).

\section{The principle of beneficence}

- One ought to prevent and remove evil or harm.

- One ought to do and promote good ([5] p. 151).

\section{The principle of nonmaleficence}

"One ought not to inflict evil or harm", where harm is understood as "thwarting, defeating, or setting back some party's interests" ([5] pp. 151-152).

\section{The principle of justice}

Beauchamp \& Childress do not think that a single principle can address all problems of distributive justice ([5] p. 241). They defend a framework for allocation that incorporates both utilitarian and egalitarian standards. A fair health care system includes two strategies for health care allocation: 1) a utilitarian approach stressing maximal benefit to patients and society, and 2) an egalitarian strategy emphasising the equal worth of persons and fair opportunity ([5] pp. 275, 281).

Figure 1: The four basic principles of the common morality. A brief formulation of the four ethical principles: the principles of respect for autonomy, beneficence, nonmaleficence, and justice $[5,24]$.

1. "Good reasons can be offered to act on the overriding norm rather than on the infringed norm".

2. "The moral objective justifying the infringement has a realistic prospect of achievement".

3. "No morally preferable alternative actions are available".

4. "The lowest level of infringement, commensurate with achieving the primary goal of the action, has been selected".

5. "Any negative effects of the infringement have been minimized".

6. "All affected parties have been treated impartially" ([5] p. 23).

Figure 2: Conditions constraining balancing. Conditions that must be met to justify infringement of one prima facie principle by another [5,28]

sense or the common morality contains only general moral standards which are abstract, universal, and content-thin, morality in the broad sense presents concrete, non-universal, and content-rich norms [26]. Hence, morality in the narrow sense may be specified into morality in the broad sense and here moral differences are recognized.

We regard the ethical theory of Beauchamp and Childress as useful for analyzing complex ethical cases of biomedicine. If we are confronted with an ethically complex case of biomedicine, morality in the narrow sense (the four principles of respect for autonomy, beneficence, nonmaleficence, and justice) are the starting point. These principles are not absolute, but rather prima facie binding in the sense that they should be fulfilled as long they are not in conflict with other principles. If two or more principles are in conflict they are to be specified and balanced. Specifying a principle means to give it action-guiding content by specifying who are involved, where does the action take place, when does the action take place, to whom or by whom is the action to be done or avoided. This specification has to be done while retaining the moral obligations in the original form of the principle. Maybe the conflict among the principles is eradicated by this specification, if not the principles are to be balanced. However, before balancing parallels or analogies can be made to past decisions of moral rights and wrongs in cases (paradigm cases), these decisions can serve as an authority for decisions in new cases. However, the analogies to past cases have to be normative analogies hence normative principles have to link the cases. This way a casuistic method is part of using Beauchamp and Childress' principles for case analysis [27].

If the conflict between principles is not eradicated by specification and drawing analogies to paradigm cases, the principles have to be balanced. Balancing is about the weight and strength of the principles and when principles are balanced one principle is infringed by another [5]. Beauchamp \& Childress propose six conditions which constrain balancing and which must be met to justify the infringement of one prima facie principle by another (Figure 2) [28].

In case analysis, principles are specified and balanced and parallels are drawn to paradigm cases. This way moral diversity is recognized in the sense that there might be no single right solution to a case as more than one solution might be morally justified solutions [27]. 
As already said, there are other theories useful for case analysis in biomedical ethics. However, we believe that the theory of Beauchamp and Childress is well argued and a good candidate for ethical case analysis. Their theory has been developed over thirty years with six revisions since the first publication. Philosophers have discussed the theory and given suggestions for improvements [29-34]. During the six editions of their work, Beauchamp and Childress have incorporated some of these suggestions; however, we will not go into this debate here.

\section{Steps in an Ethical Analysis}

We propose three steps in an ethical analysis of cellular therapies for neurodegenerative diseases.

The first step is to identify which ethical considerations or principles are at stake in the specific trial at hand. However, generally, in all clinical trials the following ethical considerations are important: Informed consent of research subjects or patients, risk analysis of possible side effects, specification of possible therapeutic effects, equitable access of patients to clinical trials, and adequate compensation should be paid to research subjects or patients (Table 2).

The second step in the ethical analysis is to collect relevant clinical information (technical or scientific information) to perform a riskbenefit analysis regarding possible side effects and to specify possible therapeutic effects for patients.

The third step is to consider whether some of the ethical principles do conflict and whether they need to be specified and balanced. Also, at this step parallels are drawn to paradigm cases.

In the following we will perform the second step in the ethical analysis of cellular therapy for $\mathrm{PD}, \mathrm{AD}$, and $\mathrm{HD}$, hence to list possible side effects and to specify possible therapeutic effects for patients (mentioned earlier in this article) and present them in (Table 3).

We can see from Table 3 that cellular therapies for neurodegenerative diseases seem to have therapeutic effects in patients (however, in HD the most promising results were shown in animal models [22] and the most common side effect reported is the risk of tumor formation by stem cells not fully differentiated into neurons upon transplantation or following viral transduction and subsequent differentiation to create iPS. This risk of tumor formation may be avoided by differentiating stem cells in culture before transplantation.

The third step in the ethical analysis is to judge whether the ethical principles at stake conflict and whether they are to be specified and balanced. For instance, in a PD trial regarding cellular replacement of ES cells differentiated into DA neurons the risk of developing tumors may be so high that it outweighs the possible therapeutic effect for the patient. In that case, the views of the physician and the patient need to be respected (respect for autonomy) and balanced. As can be seen, to perform the third step in the ethical analysis we need specific information for the actual study or trial at hand.

\section{Ethical Issues of Using Stem Cells from Fetuses and Embryos as Source for Transplantation}

Quite a few scientific articles in the field of cellular therapies stress that there are ethical and religious arguments against using tissue from developing embryos and ESCs as sources for transplantation. However, these articles do not explain what these arguments are. The ethical issues regarding the use of tissue from fetuses and ESCs for transplantation have a more basic nature than the ethical considerations directly associated with clinical trials presented above. In this section, we will first present the views of the scientists and then go into the ethical arguments against using stem cells from fetuses and embryos.

\section{Views of scientists in the field of cellular therapy}

DA neurons have been harvested from developing embryos and transplanted into PA patients. Kim and de Vellis [2] point out that "fetal tissue transplantation has grave problems associated with ethical and religious questions and logistics of acquiring fetal tissues". And Dyson and Barker [4] write that "ethical and logistical difficulties involved in the use of multiple fetuses for each PD patient undergoing transplantation means that this therapy is unlikely to ever become a routine treatment for PD". Also, these researchers indicate: "Stem cells themselves are not without ethical issues, especially ESCs, and thus the move towards iPS cells may be seen as a move towards a more ethically acceptable source of cells that also obviates concerns about tissue availability and immune rejection" [4].

Regarding the use of DA neurons from embryos to treat PA, Ganz et al. [3] wrote: "Owing to ethical and practical problems, embryonic stem cells require replacement by better-suited stem cells. As fetal tissue availability is limited and may present ethical implications, researchers searched for alternative sources of DA-secreting cells". These alternative sources could either be ESCs or MSCs; however, whereas ESCs face limitations regarding their risk of tumor formation, MSCs are good candidates for transplantation. Hence, Ganz et al. [3] write that the use of MSCs for PA "circumvents the ethical problems concerning fetal tissue usage, thus making them attractive for regenerative medicine research". These arguments are also pointed out by Dantuma et al. [35] and Lunn et al. [1] write that the "potential limitations of utilizing fetal tissue, however, include ethical concerns, and the ability to obtain adequate amounts of tissue for treatment". They conclude that key issues still remain regarding cell therapies "based on the ethical implications of utilizing fetal tissues and the dangers associated with cellular therapies such as graft overgrowth and the presence of nonneuronal cells within grafts".

As can be seen, scientists agree that there are ethical problems associated with the use of tissue from developing embryos and ESCs as sources for transplantation. Also, there is a practical problem of obtaining enough tissues from fetuses for transplantations. These scientists search for other cell sources for instance MSCs and iPS, however, they do not explain what are the ethical arguments against using tissue from developing embryos and ESCs for transplantation. Both MSCs and iPS are autologous and thereby reduce the risk of immunological rejection and they are multipotent meaning that they give rise to fewer cell types than for instance ESCs which are pluripotent. So, there are both pros and cons of searching for alternative cell sources for transplantation. Now, we will go into the ethical arguments against using stem cells from fetuses and embryos.

\section{The moral status of fetuses and embryos}

When discussing the ethics of using tissue from developing embryos and ESCs for transplantation, it is relevant to determine whether fetuses and embryos are protected by ethical principles including the principles of respect for autonomy, beneficence, nonmaleficence, and justice. Whether fetuses and embryos are protected by moral norms depends on whether or not they possess moral status. If they have moral status, they are protected by moral principles. To find out whether fetuses and embryos have moral status we need to determine which properties that confer moral status. Some theories hold that properties such as sentience and rationality are what count as properties relevant for moral 


\begin{tabular}{|l|l|l|}
\hline Ethical issues & Ethical considerations \\
\hline Informed consent of research subjects or patients & Informed consent & Basic ethical principles \\
\hline Possible side effects of specific treatment & $\begin{array}{l}\text { Risk-benefit analysis of } \\
\text { (Possible side effects are to be mentioned here) }\end{array}$ \\
\hline Possible therapeutic effects of specific treatment & (Possible therapeutic effects are to be mentioned here) \\
\hline Provide equitable access of research subjects or patients to clinical trials & Fairness & $\begin{array}{l}\text { Beneficence } \\
\text { Nonmaleficence }\end{array}$ \\
\hline Adequate compensation should be paid to research subjects & Fairness & Justice \\
\hline
\end{tabular}

Table 2: The first step in an ethical analysis. To identify ethical issues, ethical considerations, and basic ethical principles of clinical trials for cellular therapies for neurodegenerative diseases.

\begin{tabular}{|c|c|c|c|}
\hline $\begin{array}{l}\text { Disease and disease } \\
\text { model/patients }\end{array}$ & $\begin{array}{l}\text { Cellular replacement or environmental } \\
\text { enrichment }\end{array}$ & Possible side effects & Possible therapeutic effects \\
\hline $\begin{array}{l}\text { PD } \\
\text { Patients }\end{array}$ & $\begin{array}{l}\text { Cellular replacement of DA neurons from fetal } \\
\text { tissue }\end{array}$ & $\begin{array}{l}\text { Involuntary movements } \\
\text { Immune rejection } \\
\text { Not long survival of transplanted cells }\end{array}$ & $\begin{array}{l}\text { Marked symptomatic relief after } \\
\text { transplantation }\end{array}$ \\
\hline $\begin{array}{l}\text { PD } \\
\text { Rat model }\end{array}$ & $\begin{array}{l}\text { Cellular replacement of ES cells differentiated into } \\
\text { DA neurons }\end{array}$ & $\begin{array}{l}\text { Immune rejection } \\
\text { Tumor formation }\end{array}$ & Functional recovery \\
\hline $\begin{array}{l}\text { PD } \\
\text { Rodent model }\end{array}$ & $\begin{array}{l}\text { Cellular replacement of iPS differentiated into DA } \\
\text { neurons }\end{array}$ & $\begin{array}{l}\text { Tumor formation by viral transduction } \\
\text { of reprogramming factors }\end{array}$ & Improved functional deficits \\
\hline $\begin{array}{l}\text { PD } \\
\text { Rodent model }\end{array}$ & $\begin{array}{l}\text { Environmental enrichment by MSCs and NPCs } \\
\text { designed to produce growth factors to maintain } \\
\text { remaining DA neurons }\end{array}$ & & Promotion of functional recovery \\
\hline $\begin{array}{l}\text { PD } \\
\text { Rat model }\end{array}$ & $\begin{array}{l}\text { Environmental enrichment by transplanting } \\
\text { HUMSCs expressing VEGF }\end{array}$ & & $\begin{array}{l}\text { Normalization of phenotype and } \\
\text { reduced loss of dopaminergic } \\
\text { neurons }\end{array}$ \\
\hline $\begin{array}{l}\text { AD } \\
\text { Patients }\end{array}$ & $\begin{array}{l}\text { Environmental enrichment by epithelial cells } \\
\text { expressing NGF }\end{array}$ & & Results are not published yet \\
\hline $\begin{array}{l}\text { AD } \\
\text { Rodent model }\end{array}$ & $\begin{array}{l}\text { Environmental enrichment by transplanting NPCs } \\
\text { together with BDNF enhancement }\end{array}$ & & $\begin{array}{l}\text { Increased synaptic density and } \\
\text { cognitive function }\end{array}$ \\
\hline $\begin{array}{l}\text { AD } \\
\text { Mouse model }\end{array}$ & Cellular replacement of HUMSCs & & $\begin{array}{l}\text { Glial activation, reduction of } \\
\text { oxidative stress and apoptosis } \\
\text { Restoring memory and learning } \\
\text { functions }\end{array}$ \\
\hline $\begin{array}{l}\text { HD } \\
\text { Rodent model }\end{array}$ & Cellular replacement of MSNs from fetal tissue & & $\begin{array}{l}\text { MSNs integrated and formed } \\
\text { circuitry }\end{array}$ \\
\hline $\begin{array}{l}\text { HD } \\
\text { Patients }\end{array}$ & Cellular replacement of MSNs from fetal tissue & & $\begin{array}{l}\text { Minor temporary progress before } \\
\text { inherent degeneration of neurons }\end{array}$ \\
\hline $\begin{array}{l}\text { HD } \\
\text { Rat model }\end{array}$ & Cellular replacement of primed NPCs & & $\begin{array}{l}\text { Accelerate sensorimotor function } \\
\text { outcome }\end{array}$ \\
\hline $\begin{array}{l}\text { HD } \\
\text { Rodent model }\end{array}$ & $\begin{array}{l}\text { Environmental enrichment by NPCs overexpressing } \\
\text { GDNF }\end{array}$ & & $\begin{array}{l}\text { Neuronal protection and functional } \\
\text { recovery }\end{array}$ \\
\hline
\end{tabular}

Table 3: Part of the second step in an ethical analysis. To list possible side effects and to specify possible therapeutic effects (mentioned earlier in this article).

status. Others argue that there is only one property that confers moral status and, viz. human dignity. However, according to Beauchamp and Childress, the concept of human dignity is unclear and obscure and they cannot find convincing arguments justifying this concept in moral theory [5]. According to these ethicists, there is no single theory on moral status that can solve ethical issues of for instance the use of tissue from developing embryos and ESCs for transplantation, they think that different theories need to be combined to give a framework for the analysis of these cases [5]. In the following, we will go through different suggestions on which properties are relevant for having moral status and thereby for being protected by ethical principles.

Some theories maintain that only human beings (members of Homo sapiens) have moral status. So, according to these theories both human fetuses and embryos have moral status and also a person having a brain damage possesses full moral status and is protected by moral norms. However, according to Beauchamp and Childress [5] in the future using species criteria may not be as clear as it seems, for instance a monkey-human chimera designed for the purposes of stem cell research, is this chimera protected by moral norms? Other theories maintain that moral status is based on specific properties such as intelligence, or the capacity to feel pain. However, some humans lack these characteristics and some non-humans such as monkeys may possess them. Beauchamp and Childress believe that some human properties are a sufficient condition of moral status but not a necessary condition [5]. For instance, theories may maintain that moral status is based on cognitive properties such as perception, understanding, and thinking. These theories focus on the autonomous human being as having moral status, however, these theories do not protect vulnerable human beings such as fetuses morally, since these beings without cognitive properties do not possess moral status. However, generally we believe it obvious that these beings do possess some degree of moral status. The theories focusing on cognitive properties do not explain why specifically cognitive properties are morally relevant properties and thereby determine the moral status of beings. These theories lack other morally relevant properties such as being able to feel pain and pleasure. Beauchamp and Childress [5] conclude that cognitive properties are a sufficient condition of moral status but not a necessary condition.

Other theories base moral status on the properties of feeling suffering and well-being. Beauchamp and Childress believe that these properties are a sufficient condition to possess some degree of moral status. They believe that the principle of nonmaleficence is the most basic principle of morality, in that actions causing pain or suffering are morally wrong per se. These theories based on sentience protect animals and vulnerable human beings morally. However, they do not 
protect blastocysts, fetuses that are not developed enough for sentience, or brain-dead persons. Beauchamp and Childress [5] conclude that sentience is a sufficient condition for having moral status. They suggest that the theories based on sentience could tell what kind of being that has moral status and the theories based on cognitive properties could tell the degree of moral status [5].

Now we will see whether we can formulate some practical ethical guidelines for the use of tissue from the developing embryo or ESCs for transplantation. Often we see three positions: The developing embryo or the blastocyst are to be regarded as 1) simple tissue, 2) potential human life with some moral status, or 3 ) full human life with full moral status. The first position is some times supported by scientists, while the last position has many religious defenders. The second position is based on potentiality (or potential persons) so that the moral status of embryos increases during development. According to the second position, the moral status of fetuses is downgraded compared to persons because of the lack of sentient and cognitive properties [5].

Beauchamp and Childress [5] concluded that some human properties such as cognitive properties are a sufficient condition of moral status but not a necessary condition. And they maintained that the properties of feeling suffering and well-being are a sufficient condition to possess some degree of moral status. They suggested that the theories based on sentience could tell what kind of beings that have moral status and the theories based on cognitive properties could tell the degree of moral status [5]. If we follow these directions we would end up with the first or second positions: 1) That the developing embryo or the blastocyst is to be regarded as simple tissue since they lack sentient and cognitive capacities and thereby do not have moral status or 2) That the developing embryo or the blastocyst is to be regarded as potential human life with increasing moral status during development. We believe that there are good reasons to defend the second position, that the developing embryo or the blastocysts are to be regarded as potential human life with increasing moral status during development, and, thus, protected by ethical principles. Obviously, the principle of respect for autonomy cannot be applied because of the lack of cognitive properties. But the principle of nonmaleficence can be applied in the sense that harvesting cells causes destruction of the embryo. The nonmaleficence caused by destruction should be balanced with potential benefits for the patients. We would argue that this balancing should lead to the ethical requirement that the blastocyst and the developing embryo should be treated with increasing respect and only used for research where no other cellular sources available. Furthermore, we believe that the research within the field of cellular therapies for neurodegenerative diseases is so promising that we weight the potential beneficence regarding the treatment of patients and therefore support the use of tissue from the developing embryos and ESCs for transplantation.

\section{Conclusion}

Here we have gone through possible future cellular therapies including both cellular replacement and environmental enrichment for the neurodegenerative diseases $\mathrm{PD}, \mathrm{AD}$, and $\mathrm{HD}$. We have specified possible therapeutic effects and possible side effects for patients and concluded that cellular therapies may have therapeutic effects for patients and that the most commonly reported side effect is the risk of tumor formation. This risk may be avoided by differentiating stem cells in culture before transplantation.

We have argued that, generally, in all clinical trials the following ethical considerations are essential: Informed consent of research subjects or patients, risk analysis of possible side effects, specification of possible therapeutic effects, equitable access of patients to clinical trials, and adequate compensation should be paid to research subjects or patients. The related ethical principles are respect for autonomy, beneficence, nonmaleficence, and justice. The ethical theory of Beauchamp and Childress [5] is based on these principles and we conclude that this theory is a well-founded theory useful for analyzing complex ethical cases of biomedicine such as cellular therapies. By using cellular therapy for neurodegenerative diseases as a model system we have shown how to perform the three steps in an ethical case analysis using Beauchamp and Childress' principles.

Several articles on cellular therapy for neurodegenerative diseases mention that there are ethical issues associated with the use of tissue from the blastocysts and the developing embryo, however, these articles do not specify what these ethical issues are. Here we have explained that the ethical issues are related to the degree of moral status we ascribe to the blastocysts and the developing embryo. We believe that the blastocysts and the developing embryo are to be seen as potential human life with increasing moral status during development. Since the blastocysts and the embryo have moral status they are protected by ethical principles and we think that they should be treated with increasing respect and only used for research where no other cellular sources available. We conclude that research in cellular therapies for neurodegenerative diseases seem promising and we weight the potential beneficence caused by the therapeutic effect for patients and therefore believe that the use of tissue from the developing embryos and ESCs for transplantation is morally justified.

\section{References}

1. Lunn JS, Sakowski SA, Hur J, Feldman EL (2011) Stem cell technology for neurodegenerative diseases. Ann Neurol 70: 353-361.

2. Kim SU, de Vellis J (2009) Stem cell-based cell therapy in neurologica diseases: a review. J Neurosci Res 87: 2183-2200.

3. Ganz J, Lev N, Melamed E, Offen D (2011) Cell replacement therapy for Parkinson's disease: how close are we to the clinic? Expert Rev Neurother 11: $1325-1339$

4. Dyson SC, Barker RA (2011) Cell-based therapies for Parkinson's disease Expert Rev Neurother 11: 831-844.

5. Beauchamp TL, Childress JF (2009) Principles of Biomedical Ethics, (6 $6^{\text {th }}$ Edn) Oxford University Press.

6. Harris DT (2008) Cord blood stem cells: a review of potential neurological applications. Stem Cell Rev 4: 269-274.

7. Xiong $N$, Zhang Z, Huang J, Chen C, Zhang Z et al. (2011) VEGF-expressing human umbilical cord mesenchymal stem cells, an improved therapy strategy for Parkinson's disease. Gene Ther 18: 394-402.

8. Li M, Zhang SZ, Guo YW, Cai YQ, Yan ZJ, et al. (2010) Human umbilical vein-derived dopaminergic-like cell transplantation with nerve growth factor ameliorates motor dysfunction in a rat model of Parkinson's disease. Neurochem Res 35: 1522-1529.

9. Lee HJ, Lee JK, Lee H, Shin JW, Carter JE, et al. (2010) The therapeutic potential of human umbilical cord blood-derived mesenchymal stem cells in Alzheimer's disease. Neurosci Lett 481: 30-35.

10. Ali H, Bahbahani $\mathrm{H}$ (2010) Umbilical cord blood stem cells - potential therapeutic tool for neural injuries and disorders. Acta Neurobiol Exp 70: 316-324.

11. Newman MB, Davis CD, Borlongan CV, Emerich D, Sanberg PR (2004) Transplantation of human umbilical cord blood cells in the repair of CNS diseases. Expert Opin Biol Ther 4: 121-130.

12. Brundin P, Barker RA, Parmar M (2010) Neural grafting in Parkinson's disease Problems and possibilities. Prog Brain Res 184: 265-294.

13. Hagell $P$, Schrag A, Piccini $P$, Jahanshahi M, Brown R, et al. (1999) Sequentia bilateral transplantation in Parkinson's disease: effects of the second graft. Brain 122: 1121-1132. 
Citation: Ebbesen M, Pedersen FS, Andersen S, Jensen TG (2012) Ethical Perspectives on Stem Cell-based Cellular Therapies for Neurodegenerative Diseases. J Cell Sci Ther S3:003. doi:10.4172/2157-7013.S3-003

14. Soldner F, Hockemeyer D, Beard C, Gao Q, Bell GW, et al. (2009) Parkinson's disease patient-derived induced pluripotent stem cells free of viral reprogramming factors. Cell 136: 964-977.

15. Behrstock S, Ebert AD, Klein S, Schmitt M, Moore JM, et al. (2008) Lesioninduced increase in survival and migration of human neural progenitor cells releasing GDNF. Cell Transplant 17: 753-762.

16. Fjord-Larsen L, Kusk P, Tornøe J, Juliusson B, Torp M, et al. (2010) Long-term delivery of nerve growth factor by encapsulated cell biodelivery in the Göttingen minipig basal forebrain. Mol Ther 18: 2164-2172.

17. Fjord-Larsen L, Kusk P, Emerich DF, Thanos C, Torp M, et al. (2011) Increased encapsulated cell biodelivery of nerve growth factor in the brain by transposonmediated gene transfer. Gene Ther (Epub ahead of print).

18. Jucker M, Walker LC (2011) Pathogenic protein seeding in Alzheimer disease and other neurodegenerative disorders. Ann Neurol 70: 532-540.

19. Jellinger KA (2011) Interaction between pathogenic proteins in neurodegenerative disorders. J Cell Mol Med (Epub ahead of print).

20. Nakao N, Ogura M, Nakai K, Itakura T (1999) Embryonic striatal grafts restore neuronal activity of the globus pallidus in a rodent model of Huntington's disease. Neuroscience 88: 469-477

21. Cicchetti F, Saporta S, Hauser RA, Parent M, Saint-Pierre M, et al. (2009) Neural transplants in patients with Huntington's disease undergo disease-like neuronal degeneration. Proc Natl Acad USA 106: 12483-12488.

22. Cicchetti F, Soulet D, Freeman TB (2011) Neuronal degeneration in striata transplants and Huntington's disease: potential mechanisms and clinical implications. Brain 134: 641-652.

23. Vazey EM, Connor B (2010) Differential fate and functional outcome of lithium chloride primed adult neural progenitor cell transplants in a rat model of Huntington disease. Stem Cell Res Ther 1: 41
24. Ebbesen M (2009) Bioethics in Theory and Practice. PhD Thesis. Faculty of Health Sciences, Aarhus University, Denmark.

25. Beauchamp TL (1997) Comparative Studies: Japan and America. In: Kazumasa Hoshino (Ed), Japanese and Western Bioethics, Kluwer Academic Publishers, The Netherlands.

26. Beauchamp TL (2003) A defense of the common morality. Kennedy Inst Ethics J 13: $259-274$

27. Beauchamp TL (2003) Methods and principles in biomedical ethics. J Med Ethics 29: 269-274.

28. Ebbesen M (2011) Cross Cultural Principles for Bioethics. Advanced Biomedical Engineering. Edited by: Gaetano D. Gargiulo, Co-editor: Alistair McEwan. InTech.

29. Degrazia D (1992) Moving forward in bioethical theory: theories, cases, and specified principlism. J Med Philos 17: 511-539.

30. Holm S (1995) Not just autonomy--the principles of American biomedical ethics. $J$ Med Ethics 21: 332-338.

31. Strong C (2000) Specified principlism: what is it, and does it really resolve cases better than casuistry? J Med Philos 25: 323-341.

32. King N, Churchill L (2000) Ethical Principles Guiding Research on Child and Adolescent Subjects. J Interpers Violence 15: 710-724

33. Rendtorff J, Kemp P (2000) Basic ethical principles in European bioethics and biolaw. Vol 1: autonomy, dignity, integrity and vulnerability. Denmark: Centre for ethics and law.

34. Rauprich $\mathrm{O}$ (2008) Common morality: comment on Beauchamp and Childress. Theor Med Bioeth 29: 43-71.

35. Dantuma E, Merchant S, Sugaya K (2010) Stem cells for the treatment of neurodegenerative diseases. Stem Cell Res Ther 1: 37.
This article was originally published in a special issue, Central Nervous System: Cell Therapy handled by Editor(s). Dr. Alluru S. Reddi, New Jersey Medical School, USA
Submit your next manuscript and get advantages of OMICS Group submissions

Unique features:

- User friendly/feasible website-translation of your paper to 50 world's leading languages

Audio Version of published paper

Digital articles to share and explore

Special features:

200 Open Access Journal

15,000 editorial team

21 days rapid review process

Quality and quick editorial, review and publication processing

Indexing at PubMed (partial), Scopus, DOAJ, EBSCO, Index Copernicus and Google Scholar etc

Sharing Option: Social Networking Enabled

Authors, Reviewers and Editors rewarded with online Scientific Credits

- Better discount for your subsequent articles

Submit your manuscript at: http://www.editorialmanager.com/lifesciences 